\title{
Competency-Building of Rural Women Pioneers Focused on Early Detection of Breast Cancer in New Valley Governorate
}

\author{
Fatma Mohammed Ahmed ${ }^{1}$, Manal Saleh Mosalem², Amany Sobhy Sorour ${ }^{1}$ \\ ${ }^{1}$ Community Health Nursing Department, Faculty of Nursing, Zagazig University, Zagazig, Egypt \\ ${ }^{2}$ Nursing Directorate, New Valley Governorate, Kharga, Egypt \\ Email address: \\ dr.amany.sorour@gmail.com (A. S. Sorour)
}

\section{To cite this article:}

Fatma Mohammed Ahmed, Manal Saleh Mosalem, Amany Sobhy Sorour. Competency-Building of Rural Women Pioneers Focused on Early Detection of Breast Cancer in New Valley Governorate. American Journal of Nursing Science. Vol. 5, No. 3, 2016 , pp. 64-71. doi: 10.11648/j.ajns.20160503.11

Received: April 20, 2016; Accepted: April 29, 2016; Published: May 10, 2016

\begin{abstract}
Background: Worldwide, breast cancer is the leading cause of cancer deaths among women. The practice of breast self-examination can heighten women awareness about the normal breast structure and composition, such option is recommended for early detection of breast cancer. The global shortage of medical workers has increased the call for involving and training community workers as rural pioneers to bridge such gap. The present study aimed to develop competency of rural women pioneers focused on early detection of breast cancer in New Valley governorate - Egypt. Subjects and Methods: A quasi-experimental design was used with a pre post-test. Purposive sample of 82 rural women pioneers in New Valley governorate was invited to take part in the study. Besides personal data, two tools were used to collect required data; a selfadministered questionnaire sheet was prepared guided by Cancer Awareness Measure (CAM) and breast self-examination checklist adapted from the document prepared by Egypt Health Workforce Development Project. Results: More than half of the pioneers were at age group 30 to 40 , with the mean age $39.1 \pm 6.5$ years, and $78 \%$ of them had more than 10 years of experience as rural pioneers. A statistically significant difference was found between study subjects' knowledge concerning cancer risk factors \& warning signs pre-post intervention, and also in the practice of breast self-examination. Conclusion \& recommendation: Nursing educational intervention designed for community manpower can successfully enhance breast cancer knowledge and practice. On the other hand, further research is recommended to replicate the study at different settings using larger samples to permit for generalization.
\end{abstract}

Keywords: Competency Building, Rural Women Pioneers, Breast Cancer, Early Detection

\section{Introduction}

In low - and middle-income countries community awareness is a key for early detection of breast cancer. Evidence support the idea that interventions carried out by community health workers as rural Pioneers for underserved population can improve health care management, disease prevention, and health promotion. Community health workers (CHWs) improve management of chronic illnesses such as asthma, diabetes, maternal \& child health issues, increase health promotion activities such as vaccinations and cancer screening, and demonstrate net cost savings [1-3].

CHWs in order to serve in outreach settings to increase access and effective utilization of health care and social services, chiefly for minority and disadvantaged communities; they assist their neighbors to negotiate systems, ensure that families receive the services they need, and provide culturally appropriate health education, information, and support in a family's primary language [4].

CHWs can play a significant role in obtaining information from families, providing basic education, and facilitating access to medical care [5]. A coordinated care model explained by Stout et al. [6] clarified that $\mathrm{CHWs}$ were integrated into a clinical team and served as the liaison 
between the family and clinic. In the same stream, Krieger et al. [7] labeled community workers interventions that included in home environmental assessments, education, support for behavior change, and resources.

People belonging to ethnic minority group or lower socioeconomic status are known to have particularly low awareness of cancer risk factors and signs \& symptoms [8]. They are also less probably to join cancer screening programs [9-10]. What's more, such groups tend to have not as good access to health information which exacerbates inequalities in awareness and health outcomes. Variety of community based staff as nurses, health trainers/champions, stop smoking specialists, and physical activity \& weight management coordinators, are employed by public health organizations to engage with public on an individual basis for encouraging health behavior change. Such staff members are well placed to publicize key messages about cancer, but because it is not the focus of their role, they are not always supported with sufficient knowledge to do so [11].

For going some way towards early diagnosis of cancer, population has to be encouraged for earlier presentation of cancer which could be achieved through improving their knowledge regarding early warning signs [12]. A small number of studies referred to the training of health care workers to promote cancer screening in underserved populations, but training was limited to the screening of one cancer and didn't address any education regarding cancer risk factors, and signs \& symptoms [13, 14].

Cancer is a leading cause of death globally. The World Health Organization (WHO) [15] estimates that 7.6 million people died of cancer in 2005 and 84 million people will die in the next 10 years if action is not taken. More than $70 \%$ of all cancer deaths occur in low- and middle-income countries, where resources available for prevention, diagnosis and treatment of cancer are limited or nonexistent.

Breast cancer is by far the most common cancer among women of both developed and developing countries accounting for $22.9 \%$ of all female cancers. It is also the leading cause of cancer death in females accounting for $13.7 \%$ of their cancer related mortality [16]. In Egypt, breast cancer is estimated to be the most common cancer among females accounting for $37.7 \%$ of their total with 12,621 new cases in 2008. It is also the leading cause of cancer related mortality accounting for $29.1 \%$ of their total with 6546 deaths [16]. These estimates are confirmed in many regional Egyptian cancer registries [17, 18].

Every year, millions of cancer patients could be saved from premature death and suffering if they had timely access to early detection and treatment. Early detection is based on the concept that the sooner in its natural history the cancer is detected, the more effective the treatment is likely to be. Worldwide, about a third of all cancers are estimated to be amenable to early detection and potential cure with treatment. If cancer is detected early, within a comprehensive cancer control plan, a significant number of cancer patients can be cured or have their lives prolonged significantly. Without early detection, treatment costs rise substantially, resources are used inefficiently and the need for palliative care services increases unnecessarily [15].

The target population and health-care providers should be continuously educated to understand that cancer, when diagnosed early, is far more likely to respond to effective treatment. This information can be provided within or outside the health facility, by a variety of health workers, community leaders and traditional healers who need to be appropriately trained [15].

\subsection{Significance}

Besides poverty, low public awareness of breast cancer is a barrier to breast cancer control in low- and middle-income countries where women seek medical help late and cancers are often diagnosed at advanced stages when very little can be done in terms of curative treatment. For early detection, efforts must be devoted to improve community awareness that can play an important role in breast cancer control [19].

Internationally, a global shortage of medical workers has increased the call for these types of personnel. Significant health care workforce shortages are present in 57 countries, including countries in sub-Saharan Africa, Bangladesh, India, and Indonesia [20]. Training and involving CHWs in breast cancer awareness program will reinforce the sustainability of the improved knowledge, attitude \& practice and the necessary link between the knowledge gained and seeking early medical help. Few studies meeting the inclusion criteria that described the training of CHWs, all included studies reported evidence of improvement in knowledge or skills, and many focused on aspects of training relevant to the specific health concern. Ministry of Health and other policy makers should focus on such interventions. In addition, collaborations between all existing services and society organizations must be enhanced. [21].

Research article was done by Ibrahim et al. [22] to present cancer incidence rates at national and regional level of Egypt, based upon results of National Cancer Registry Program (NCRP), which stratified Egypt into 3 geographical strata: lower, middle, and upper. Results revealed that in females, breast and liver cancer occupied the top ranks accounting for around $45 \%$ of all cancers. Unfortunately, regions that were not covered were frontier governorates; namely Matrooh, New Valley, Red Sea, and Sinai due to logistic reasons. Henceforth, the aim of the existing study was to develop competency of rural women pioneers focused on early detection of breast cancer in New Valley governorate - Egypt.

\subsection{Hypothesis}

Nursing intervention can improve competency of rural women pioneers as regards early detection of breast cancer.

\section{Subjects and Methods}

\subsection{Design}

A quasi-experimental design was used with a pre post-test. 


\subsection{Setting}

The New Valley governorate lies in the South West of the Arab Republic of Egypt. It is by far one of the largest governorates in Egypt $(440098.00 \mathrm{Km} 2)$ about $44 \%$ of the total area of Egypt [23]. On the contrary to its size is considered one of the fewest population size governorates in Egypt with a total population of around 233 thousand by March 2016 according to Central agency for Public Mobilization and Statistics [24]. But the inhabitants are sporadic throughout the governorate where it is difficult for many to travel for seeking medical advice henceforth, it was important to empower rural women pioneers with adequate knowledge and practice to create such a liaison.

\subsection{Sample}

A purposive sample of rural women pioneers in New Valley governorate was invited to take part in the study. Participants were selected from four districts (Kharga, Dakhla, Paris, and Palat). All the pioneers were invited to join in, out of 115 pioneer 103 managed to attend the program, but only 82 completed the questionnaire. The other pioneers couldn't participate because they had to travel hundreds of kilometers.

\subsection{Instruments}

Besides personal data, two tools were used to collect required data; the first one was a self-administered questionnaire sheet was prepared guided by Cancer Awareness Measure (CAM) developed by Stubbings et al. [25] to assess participants knowledge and perceived barriers. It included questions about warning signs, risk factors, perceived barriers that might hinder people from seeking medical advice, most common cancer types in men and women, and the correct time of seeking medical care when suspecting cancer signs. For warning signs response options were 'Yes' which scored 1, and 'No'/'Don't know' which scored zero. For risk factors 5-point Likert agreements scale ('strongly agree', 'agree' which scored 1 , and 'not sure', 'disagree'\& 'strongly disagree' which scored zero). The second tool was breast self-examination checklist adapted from the document prepared by Egypt Health Workforce Development Project (HWD) [26], with 3 point Likert scale 'satisfactory' which scored 2, 'unsatisfactory' which scored 1 , and 'not done' which scored zero.

\subsection{Scoring}

Warning sign scores were added together to give a total score (with a maximum score of 9), where score $\geq 50 \%$ ( 5 points or more) was considered as adequate knowledge. As to risk factors, also scores were added together to give a total score (with a maximum score of 11 ), where score $\geq 50 \%$ (6 points or more) was considered as adequate knowledge. Relating to breast self- examination checklist, scores were added together to give a total score (with a maximum score of 30$)$, where score $\geq 50 \%$ (15 points or more) was considered satisfactory.

\subsection{Field Work}

Firstly, a letter was issued to the directorate of health affairs to gain acceptance for holding the training program. Once permission was granted, an invitation letter containing the aim of the study was sent to all the administration for inviting the pioneers to take part in the program. Then, a pilot study was conducted on 10 pioneers (were included in the main study sample) to test the feasibility, clarity of the tools and to estimate the time required for collecting data. After that, two successive days were scheduled for implementing the program for each administration, starting from December $7^{\text {th }}$ to December 28, 2016. Finally, the program was carried out over four sessions ( 2 hours per day, with rest break inbetween), while the number of participants ranged from 15 to $35 /$ administration. The first day started with the pre-test and identification as icebreaking, and through lectures, group discussion and demonstration the program was implemented, followed by post-test in the second day.

\subsection{Ethical Consideration}

Informed consent was waived since no personally identifiable information was obtained. Participants were informed that they have the right to withdraw at any time, their participation is voluntary and the information gathered is for research purpose only.

\subsection{Data Analysis}

Scores were calculated for each participant and continuous variables were summarized by mean and standard deviation and categorical variables were summarized by frequencies. Paired sample t-test was used to determine whether there is statistical evidence that the mean difference between paired observations on a particular outcome is significantly different from zero (significance level was at .05). Data were analyzed using statistical package for social sciences (SPSS version 14).

\section{Results}

General characteristics of rural women pioneers, results reveal that more than half of the study sample $(54.9 \%)$ was at age group 30 to 40 , with the mean age $39.1 \pm 6.5$ years. Most of them $(90.2 \%)$ were married and having middle education. The majority $(86.6 \%)$ of them was from rural area and $78 \%$ have more than 10 years of experience as rural pioneers.

As to medical care seeking barriers as perceived by rural women pioneers, table 1 clarifies that study sample inferred that barriers to seeking medical help might be due to scary and worry $(85.4 \%$ \& $59.8 \%$ respectively), while minority $(15.9 \%)$ of them inferred barriers to difficulty in making medical appointment.

With reference to Pre - Post intervention changes in satisfactory knowledge, Figure 1 illustrates that the post intervention results showed improvement in satisfactory knowledge regarding risk factors. The least recognized risk factors before the intervention were being over 70 years old and getting sunburnt more than once as a child $(8.5 \%$ and 
$6.1 \%$ respectively), while exposure to another person's cigarette and drinking alcohol were the most recognized risk factors $(84.1 \%$ and $82.9 \%)$ post intervention. Regarding warning signs, figure 2 depicts that the least recognized warning signs pre intervention were persistent cough, difficulty swallowing, and unexplained pain (13.4\%, $20.7 \%$, and $22 \%$ respectively), while the most recognized warning signs were persistent change in bowel habits, sore that doesn't heel, and lump or swelling $(84.1 \%, 86.6 \%$, and $95.1 \%$ respectively). In addition, Figure 3 portrays that the pre-post intervention percent of change in pioneers' knowledge regarding common cancer types among women and men exceeded $50 \%$, compared to more than $40 \%$ for immediacy of seeking medical care.
Table 1. Medical care seeking barriers as perceived by rural women pioneers $(n=82)$.

\begin{tabular}{lll}
\hline Barrier & \multicolumn{3}{l}{ No (82) \% } \\
\hline Emotional & 46 & 56.1 \\
Too embraced & 70 & 85.4 \\
Too scared & 49 & 59.8 \\
Worried about what doctor can find & 22 & 26.8 \\
Not confident to talk about symptoms & & \\
Practical & 25 & 30.5 \\
Too busy & 21 & 25.6 \\
There are other things to worry about & 24 & 29.3 \\
Difficult to arrange to transport & & \\
Service & 19 & 23.2 \\
Fear of wasting doctor time & 21 & 25.6 \\
Difficult to talk to doctor & 13 & 15.9 \\
Difficult to make appointment & & \\
\hline
\end{tabular}

Responses are not mutually exclusive

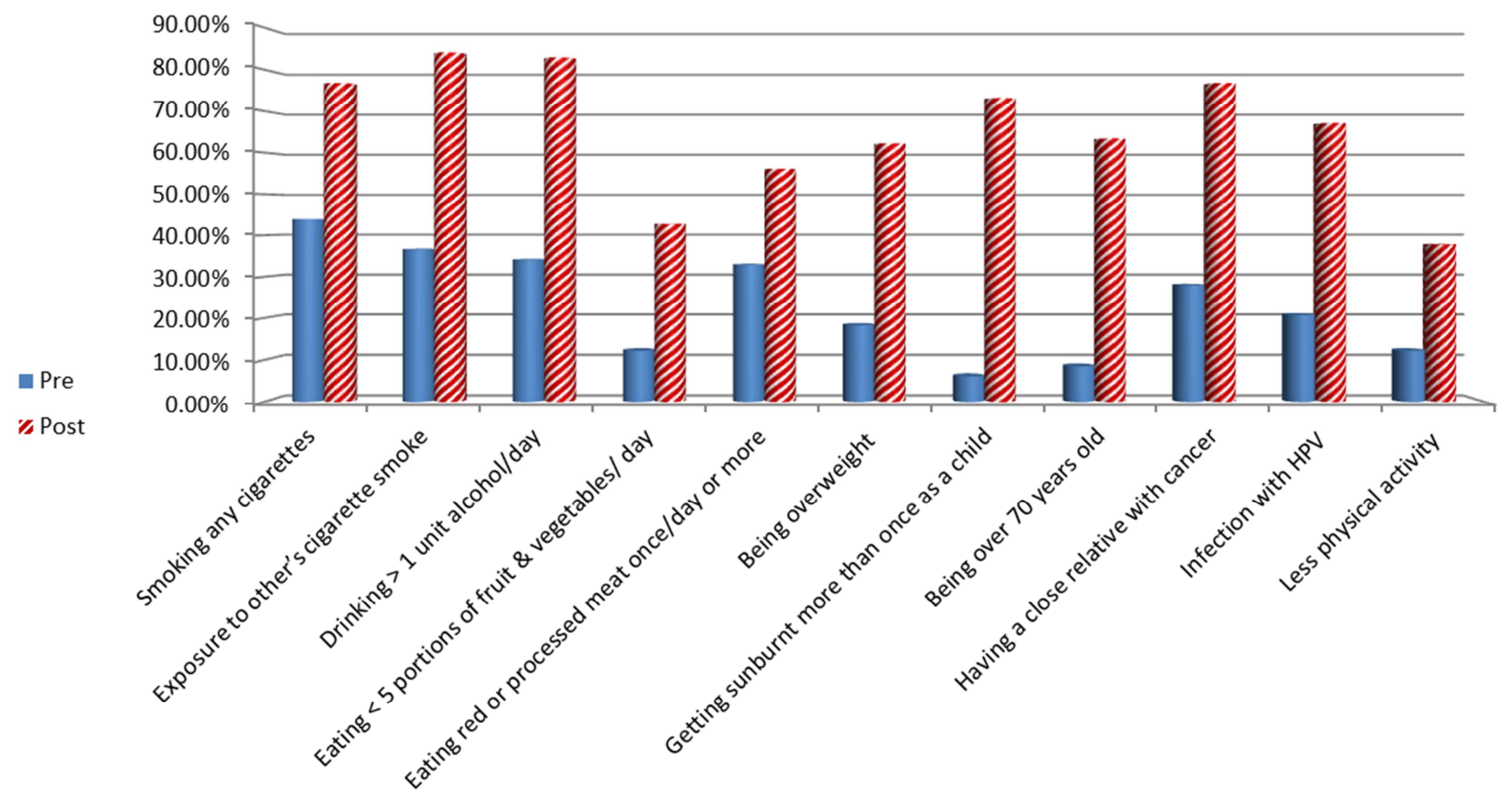

Figure 1. Pre - Post intervention changes in satisfactory knowledge regarding risk factors of breast cancer among study sample ( $n=82$ ).

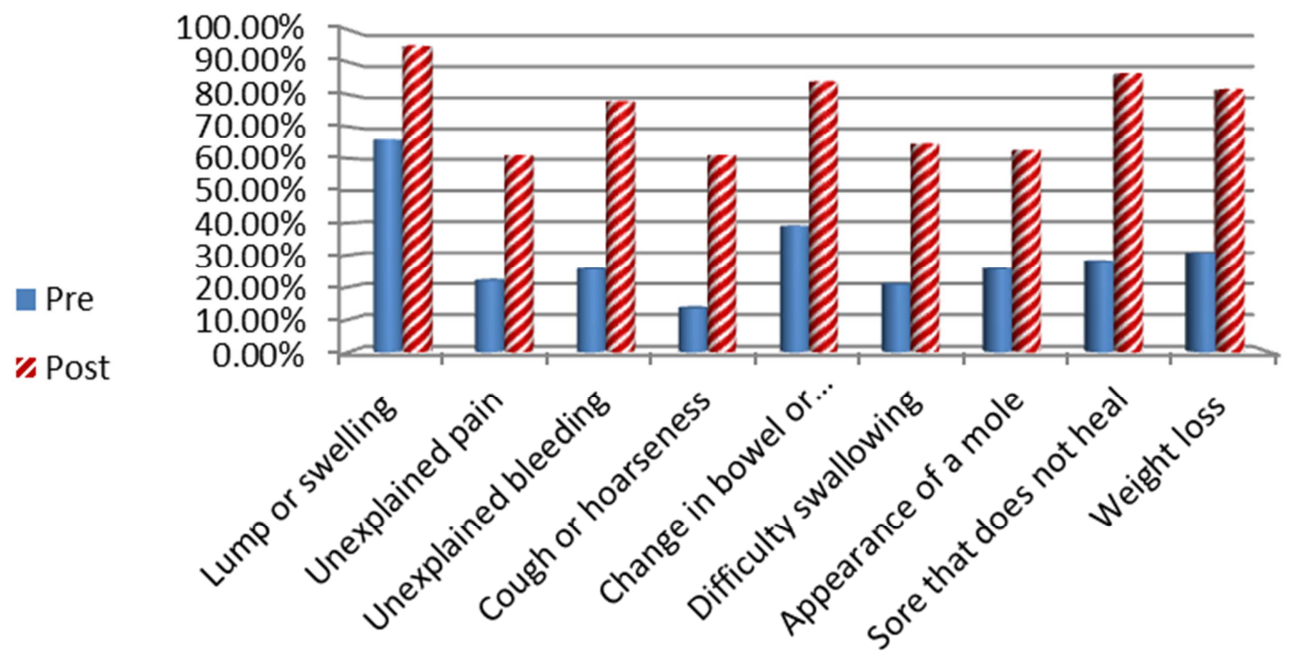

Figure 2. Pre - Post intervention changes in satisfactory knowledge regarding warning signs of breast cancer among study sample ( $n=82$ ). 


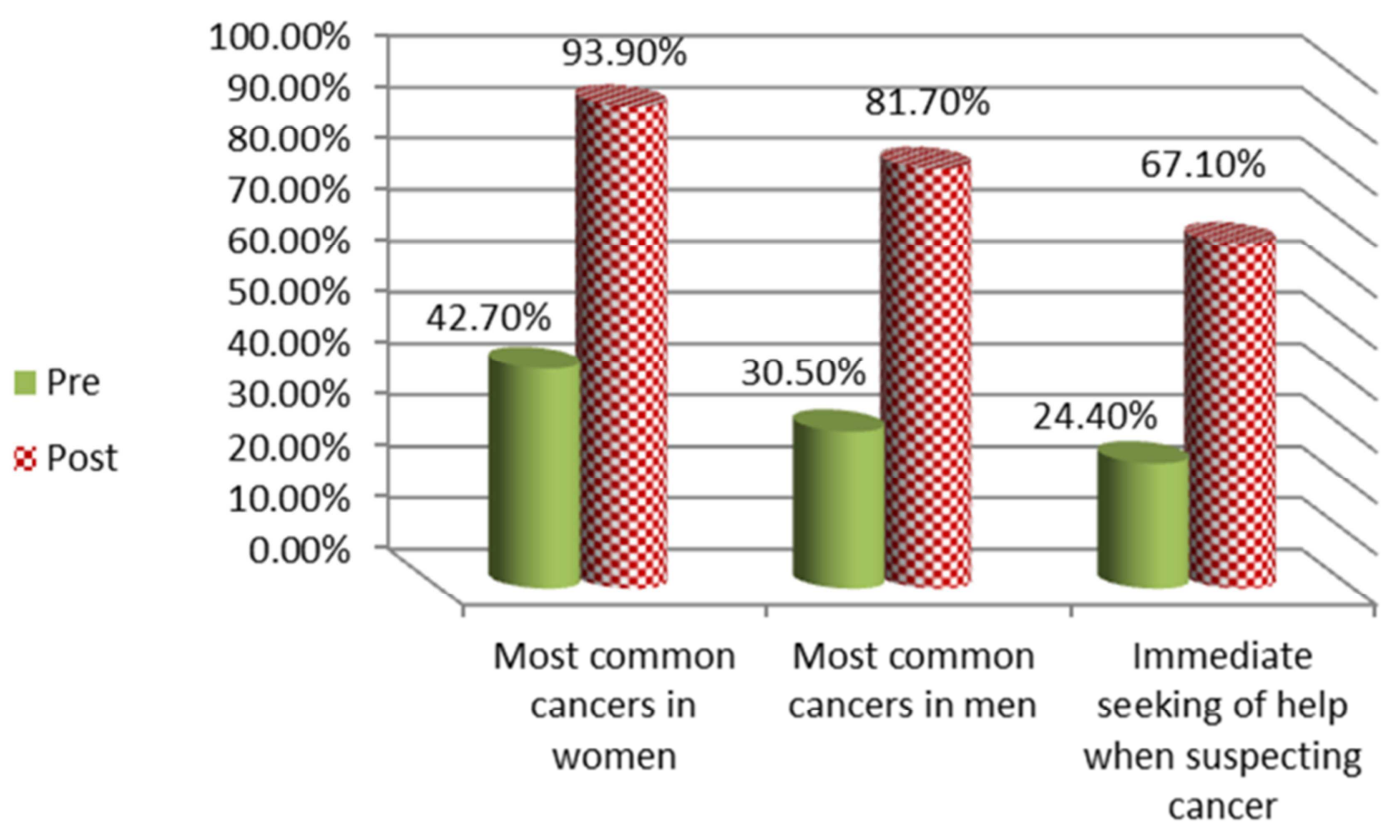

Figure 3. Pre Post intervention changes in knowledge regarding common cancer types and time of seeking medical care among study sample ( $n=82$ ).

Table 2. Pre-Post changes in satisfactory practice of breast self-examination among study sample ( $n=82)$.

\begin{tabular}{|c|c|c|c|c|}
\hline \multirow{2}{*}{ Step } & \multicolumn{2}{|l|}{ Pre } & \multicolumn{2}{|c|}{ Post } \\
\hline & No & $\%$ & No & $\%$ \\
\hline Begin while lying in bed & 8 & 9.8 & 77 & 93.9 \\
\hline Place a pillow or folded towel under left shoulder and left hand behind head & 10 & 12.2 & 77 & 93.9 \\
\hline $\begin{array}{l}\text { Shoulder should be raised high enough for left breast to be center on top of chest. Falling neither to the center nor toward the } \\
\text { armpit. }\end{array}$ & 37 & 45.1 & 71 & 86.6 \\
\hline Use your right hand to examine left breast, and vice-versa. & 58 & 70.7 & 77 & 93.9 \\
\hline $\begin{array}{l}\text { Use two or three fingers, keeping the thump extended, and always feel with the sensitive "palmer pads" on the flat, inner } \\
\text { surfaces of fingers. }\end{array}$ & 46 & 56.1 & 78 & 95.1 \\
\hline Examine the entire area, including the lymph nodes, from collar bone to just below breasts, and from armpits to breast bone. & 43 & 52.4 & 75 & 91.5 \\
\hline Start in the underarm area and have fingers move downward little by little until reaching the area below the breast. & 42 & 51.2 & 75 & 91.5 \\
\hline Move fingers slightly toward the middle and slowly move back up. Go up and down until the entire area is covered. & 43 & 52.4 & 74 & 90.2 \\
\hline Press gently but firmly to immobilize the skin and roll fingertips over the underlying tissue. & 32 & 39 & 71 & 86.6 \\
\hline Go over each area three times using light pressure, medium pressure and firm pressure & 24 & 29.3 & 71 & 86.6 \\
\hline Repeat the entire examination with your left arm in a relaxed position at side. & 17 & 20.7 & 68 & 82.9 \\
\hline Shift the pillow to right side. & 11 & 13.4 & 73 & 89 \\
\hline Examine your right breast with left hand, in both the arm overhead and arm-at-side position. & 34 & 41.5 & 71 & 86.6 \\
\hline At the mirror with upper body unclothed examine the appearance of breast & 47 & 57.3 & 76 & 92.7 \\
\hline Press nipple gently to check for the presence of secretions or strange liquids, or strange masses. & 48 & 58.5 & 74 & 90.2 \\
\hline \multicolumn{5}{|l|}{ Total satisfactory practice level } \\
\hline Satisfactory & 45 & 54.9 & 82 & 100 \\
\hline Unsatisfactory & 37 & 45.1 & - & - \\
\hline
\end{tabular}

Table 3. Difference between pre-post intervention changes in study subjects' knowledge concerning cancer risk factors \& warning signs, and breast selfexamination $(n=82)$.

\begin{tabular}{lllllll}
\hline \multirow{2}{*}{ Item } & Pre & & Post & & \multirow{2}{*}{ t test } & \\
\cline { 2 - 6 } & Mean & SD & Mean & SD & -18.29 & .000 \\
Cancer risk factors & 2.53 & 1.7 & 7.23 & 2.3 & -14.19 & .000 \\
Cancer warning signs & 2.7 & 1.8 & 6.74 & 2 & -13.84 & .000 \\
Breast self-examination & 15.9 & 7.7 & 28 & 3.6 & & \\
\hline
\end{tabular}

Concerning Pre-Post changes in satisfactory practice of breast self-examination among study sample, table 2 reveals that the post- test findings presented progress in overall practice of breast self-examination.

Table 3 clarifies a statistically significant difference between study subjects' knowledge concerning cancer risk factors \& warning signs pre-post intervention, and also in the practice of breast self-examination where $\mathrm{t}=-18.29,-14.19$, and -13.84 respectively $(\mathrm{P}$ value $=.000)$. 


\section{Discussion}

Breast cancer is one of the well-known cancers affecting women in developing countries, prevention or identification of the disease at an early stage is of paramount importance in saving as well as improving the quality of life. Breast health awareness appears to be a practical method for prevention. Training CHWs in such area and equipping them with information can help increase reach, and create a larger 'pool' of contacts to support health engagement activities [27]. Rural pioneers as a CHWs, by virtue of their role as a bridge to the health care system, can help to propagate widely effective interventions to groups who are hardly benefit from health care advances. Such interventions are more effective for some disease prevention [21].

In relation to barriers for seeking medical help as perceived by the study sample, the study results elaborated that the highest barriers might be due to scary and worry about what doctor can find. These findings reflect the cultural and the psychological aspects of the study sample, as cancer is usually discovered in late stages when there is nearly nothing to do except bearing pain and medication. Also this result might reflect the lower socioeconomic status population fears' of not having enough money to afford treatment costs.

On the same way Robb et al. [8] found that the most widely endorsed barriers to consultation were difficulty making an appointment (37\% men, 45\% women), not wanting to 'waste the doctor's time' (36\% men, $41 \%$ women) and worry about what the doctor might find (34\% men, $40 \%$ women). On the other hand, Oluwole and Al-Naggar et al. $[28,29]$ found that the main identified barriers that hinder women to practice breast self-examination were lack of information and forgetfulness.

Prior to the intervention, study results revealed that knowledge regarding risk factors, signs and symptoms of breast cancer and most common types of cancer were inadequate. These findings might reflect the lack of awareness of breast cancer among study sample. On the same way, WHO [15] emphasized the importance of awareness in early detection of breast cancer.

Post intervention results of the present study showed marked improvement in knowledge regarding all studied cancer aspects. This might be attributed to the positive effect of the intervention and reflected the willingness of the study sample to attain such knowledge. Improving the knowledge of early warning signs among the general population could help to encourage earlier presentation and therefore go some way towards promoting earlier diagnosis and management. Additionally, population should be educated about the common cancers and about the risk factors and lifestyles that make individuals liable to such cancers. Avoiding risk factors and modifying lifestyles will help to minimize the incidence of cancers.

Similarly, a study done in India by Rao et al. [30] indicated significant increase in overall awareness regarding breast cancer and the various aspects pertaining to it $(\mathrm{z}=-15.807$ $\mathrm{P}<0.001$ ). Additionally, a study carried out in Turkey by Ceber, et al. [31] described a training program designed to educate midwives about breast self-examination and breast cancer. The authors reported improvements in trainees' knowledge of breast cancer symptoms. Moreover, Mena et al. [32] stated that, the effect of the Breast Care International (BCI) awareness program on obtaining high knowledge declared that participants who attended the program were significantly more likely to obtain higher knowledge scores and to state practicing breast self-examination. The BCI program improved knowledge, attitude and practice toward breast cancer.

Study results showed that the pre intervention practice of breast self-examination was satisfactory among 45 participants $(54.9 \%)$, which reflect that they are somewhat aware with such aspect of early detection of breast cancer. This result might be attributed to their work in the field of health as a rural pioneers, also the different types of media in Egypt spot light on the practice of breast self-examination and its importance as a simple \& not expensive cancer screening tool. In somewhat similar context, the study of Alkhigbe and Omuemu's [33] which conducted in urban Nigeria and revealed that $77.6 \%$ of the respondents performed breast self-examination because the city environment provides a reasonable location to educate women on the importance of breast self-examination and how the women should examine their breasts.

On the other hand, study conducted by Maqsood et al. [34] revealed poor practice regarding breast self-examination by women in Pakistan where $63.1 \%$ of the respondents had never heard of screening tests or did not feel any need to perform breast self-examination. These findings concurred with the study findings by Mothobi [35] in Zimbabwe, showed that the practice of breast self-examination among the subjects was poor, as $53(62.4 \%)$ of women had never practiced breast self-examination.

Such discrepancy between the results might be attributed to differences in culture, educational levels, health policies and $\&$ services provided in each country, also community attitude toward health.

Post intervention results revealed an improvement in all steps of breast self-examinations. These results might be attributed to the importance of the nurses' role in facilitating health promoting behavior to the women in breast selfexamination. The health care givers have a central role in the improvement of practices of breast self-examination. Similarly, a study carried out by Luszczynska [36], recruited 720 college-aged women for an intervention designed to enhance self-efficacy in order to increase breast selfexamination performance. Results indicated that, compared to the control group, participants in the intervention group exhibited significantly greater behavior change. Moreover, in a study done In Egypt by Mohamed et al., [37], the results showed that participants' knowledge of breast cancer increased significantly after the education with significance difference in knowledge of blind girl's between pre and post educational program, as well as in practices of breast selfexamination. Blind girls felt confident to the teaching personnel and were willing to hear information about breast 
cancer and breast self-examination.

American Cancer Society [38] emphasized that although curative treatment for breast cancer is increasingly successful, early detection and treatment are critical in reducing mortality rates among women.

\section{Conclusion and Recommendations}

This study demonstrates that inexpensive educational intervention utilizing existing community manpower can successfully enhance breast cancer knowledge and practice. Further research is recommended to replicate the study at different settings using larger samples to investigate knowledge and practice regarding breast self-examination in order for the results to be generalizable. Additionally, there is a need to carryout studies on how the barriers of seeking medical help can be alleviated.

\section{References}

[1] Viswanathan, M., Kraschnewski. J., Nishikawa, B., et al. (2009): Outcomes of community health worker interventions. Evid Rep Technol Assess. Assessment No. 181. AHRQ Publication No. 09-E014. Rockville, MD: Agency for Healthcare Research and Quality.

[2] The New England Comparative Effectiveness Public Advisory Council. Community health workers: a review of program evolution, evidence on effectiveness and value, and status of workforce development in New England: The Institute for Clinical and Economic Review. [Online]. 2013 [Cited 2014 Apr $\left.2^{\text {nd }}\right]$. Retrieved from http://cepac.icer-review.org/wpcontent/uploads/2011/04/CHW-Final-Report-07-26-

MASTER1.pdf

[3] Massachusetts Department of Public Health. Community health workers in Massachusetts: improving health care and public health. [Online]. 2009 [Cited 2014 Apr $6^{\text {th }}$ ]. Retrieved from http://www.mass.gov/eohhs/docs/dph/ com-health/comhealth-workers/legislature-report.pdf

[4] Swider, S. M. (2002): Outcome effectiveness of community health workers: An integrative literature review. Public Health Nursing, 19 (1), 11-20.

[5] Butz, A. M., Malveaux, F. J., Eggleston, P., Thompson, L., Schneider, S., Weeks, K., et al. (1994): Use of community health workers with inner-city children who have asthma. Clinical Pediatrics (Phila), 33 (3), 135-141.

[6] Stout, J. W., White, L. C., Rogers, L. T., McRorie, T., Morray, B., Miller-Ratcliffe, M., et al. (1998): The Asthma Outreach Project: a promising approach to comprehensive asthma management. Journal of Asthma, 35 (1), 119-127.

[7] Krieger, J. W., Takaro, T. K., Song, L., and Weaver, M. (2005): The Seattle-King County Healthy Homes Project: A randomized, controlled trial of a community health worker intervention to decrease exposure to indoor asthma triggers. American Journal of Public Health, 95 (4), 652-659.

[8] Robb, K., Stubbings, S., Ramirez, A., Macleod, U., Austoker, J., Waller, J., et al. (2009): Public awareness of cancer in Britain: A population-based survey of adults. British Journal of Cancer; 101: S18-23.
[9] Von Wagner, C., Baio, G., Raine, R., Snowball, J., Morris, S., Atkin, W., et al. (2011): Inequalities in participation in an organized national colorectal cancer screening programme: Results from the first 2.6 million invitations in England. International Journal of Epidemiology; 40: 712-8.

[10] Bang, J. Y., Yadegarfar, G., Soljak, M., and Majeed, A. (2012): Primary care factors associated with cervical screening coverage in England. Journal of Public Health; 34: 532-8.

[11] Viswanath, K. (2005): Science and society: The communications revolution and cancer control. Nature Reviews: Cancer; 5: 828-35.

[12] Parkin, D. M. (2011): The fraction of cancer attributable to lifestyle and environmental factors in the UK in 2010. British Journal of Cancer; 105: S2-5.

[13] Nguyen, T. T., Love, M. B., Liang, C., Fung, L. C., Nguyen, T., Wong, C., et al. (2010): A pilot study of lay health worker outreach and colorectal cancer screening among Chinese Americans. Journal of Cancer Education; 25: 405-12.

[14] Maxwell, A. E., Danao, L. L., Cayetano. R. T., Crespi, C. M., and Bastani, R. (2012): Evaluating the training of Filipino American community health advisors to disseminate colorectal cancer screening. Journal of Community Health; 37: 1218-25.

[15] World Health Organization (2007): Cancer control: knowledge into action: WHO guide for effective programmes; WHO Library Cataloguing-in-Publication Data, Switzerland.

[16] Ferlay, J., Shin, H. R., Bray, F., Forman, D., Mathers, C., and Parkin, D. M. GLOBOCAN. Cancer Incidence and Mortality Worldwide: IARC Cancer Base v1. 2, No. 10. Lyon, France: International Agency for Research on Cancer. [Online]. 2008 [Cited 2012 Sept 24 $4^{\text {th }}$. Retrieved from http://www.globocan.iarc.fr/factsheets/cancers/breast.asp $>; 2010$

[17] The National Cancer Registry Program of Egypt (NCRPE). Reports and Statistics: Aswan, Damietta \& El-Minia [Online]. 2012 [Cited 2012 Sept $5^{\text {th }}$ ]. Retrieved from http://www.cancerregistry.gov.eg/reports.aspx.

[18] The Gharbiah Population-based Cancer Registry (GPCR). Cancer in Egypt, Gharbiah. 2007 [Online]. [Cited 2012 Sept $\left.5^{\text {th }}\right]$. Retrieved from http://www.emro.who.int/ncd/pdf/cancer_registry_Egypt.pdf

[19] Azenha, G., Bass, L. P., Caleffi, M., et al. (2011): The role of breast cancer civil society in different resource settings. Breast; 20 (Suppl 2): S81-S87.

[20] Dastro, J., and Stone, B. (2008): Improving therapeutic outcomes in BPH through diagnosis, treatment and patient compliance. Am J MedeC; 121 (8 Suppl 2): S27-33.

[21] Viswanathan, M., Kraschnewski, J., Nishikawa, B., Morgan, L. C., Thieda, P., Honeycutt, A., Lohr, K. N., and Jonas, D. (2009): Outcomes of Community Health Worker Interventions. Evidence Report/Technology Assessment No. 181 (Prepared by the RTI International-University of North Carolina Evidence-based Practice Center under Contract No. 2902007 10056 I) AHRQ Publication No. 09-E014. Rockville, MD: Agency for Healthcare Research and Quality.

[22] Ibrahim, A. S., Khaled, H. M., Mikhail, N., Baraka H., and Kamel, H. (2014): Cancer Incidence in Egypt: Results of the National Population-Based Cancer Registry Program. Journal of Cancer Epidemiology; Article ID 437971, 18 pages. http://dx.doi.org/10.1155/2014/437971 
[23] Egypt State Information Service. New Valley Governorate. [Online]. 2013 [Cited 2016 Mar 11 ${ }^{\text {th }}$. Retrieved from http://www.sis.gov.eg/En/Templates/Articles/tmpArticles.asp $\mathrm{x}$ ?ArtID=68577\#.VuKrnUCTu1s

[24] Central agency for Public Mobilization and Statistics. Population clock. [Online]. 2016 [Cited 2016 Mar 25 $5^{\text {th }}$. Retrieved http://www.capmas.gov.eg/Pages/populationClock.aspx

[25] Stubbings, S., Robb, K., Waller, J., Ramirez, A., Austoker, J., Macleod, U., Hiom, S., and Wardle, J. (2009): Development of a measurement tool to assess public awareness of cancer. Br J Cancer; 101 Suppl 2: S13-S17.

[26] Egypt Health Workforce Development Project. (2006). Clinical Learning Guides and checklists to facilitate learning and assessment of core competencies. P. p. 11-12

[27] Wood, R. Y., Duffy, M. E., Morris, S. J., and Carnes, J. E. (2002): The effect of an educational intervention on promoting breast self-examination in older African American and Caucasian women. Oncol Nurs Forum; 29: 1081-90

[28] Oluwole, O. C. (2008): Awareness, knowledge and practice of breast -Self Examination amongst Female Health Workers in A Nigerian Community, Sudan, JMS, 3 (2), 99-104.

[29] Al-Naggar, R. A., Al-Naggar, D. H., Bobryshev Y. V., Chen R. and Assabri, A. (2011): Practice and barriers toward Breast Self-Examination among Young Malaysian Women, Asian Pacific Journal of Cancer Prevention, 12, 1173-78.

[30] Rao, R. S., Suma, N., Nair, N. S., and Kamath, V. G. (2005): Acceptability And Effectiveness Of A Breast Health Awareness Programme For Rural Women In India. Indian $J$ Med Sci, 59 (9).

[31] Ceber, E., Turk, M., and Ciceklioglu, M. (2010): The effects of an educational program on knowledge of breast cancer, early detection practices and health beliefs of nurses and midwives. Journal of Clinical Nursing; 19: 2363-71.

[32] Mena, M., Wiafe-Addai, B., Sauvaget, C., Ali, I. A. Wiafe, S. A., Dabis, F. Anderson, B. O., Malvy, D. and Sasco, A. J. (2014): Evaluation of the impact of a breast cancer awareness program in rural Ghana: A cross-sectional survey. Int. J. Cancer; 134, 913-924 VC 2013 UICC

[33] Akhigbe, A. O., and Oтиети, V. O., (2009): Knowledge, attitudes and practice of breast cancer screening among female health workers in Nigeria urban city. PubMed BMC Cancer. 9: 203.

[34] Maqsood, B., Zeeshan, M, M., Rehman, F., Aslam, F., Zafar, A., Syed, B., Qadeer, K. Ajmal, S., and Imam, S. Z., (2009): Breast cancer screening practices and awareness in women admitted to a tertiary care hospital of Lahore, Pakistan. PubMed U. S. National Library of Medicine; 59 (6): 418-21.

[35] Mothobi, M. N. (2010): The Relationship Between Knowledge Of Breast Self-Examination And Practices Regarding Breast Self-Examination Among Women Aged 25 - 49 Years At Mbare Family Services Clinic In Harare, Zimbabwe. Dissertation submitted in partial fulfillment of the Masters of Science Degree in Nursing Science, University Of Zimbabwe.

[36] Luszczynska, A. (2004): Change in breast self-examination behavior: Effects of intervention on enhancing self-efficacy. International Journal of Behavioral Medicine, 11, 95-103.

[37] Mohamed, N. A., El-Magrabi, N. M. and Ahmed, S. S. (2013): Evaluation of Breast Cancer Knowledge and Breast SelfExamination Practices among Adolescent Blind Girl's in Qena Governorate. Life Science Journal; 10 (2).

[38] American Cancer Society (2009): Cancer facts and figures2009-2010. Atlanta, GA: American Cancer Society. 